\title{
Determination of mechanical properties for wood pellets used in DEM simulations**
}

\author{
Eutiquio Gallego ${ }^{1}{ }^{*}$, José María Fuentes ${ }^{1}{ }^{(}$, Ángel Ruiz $^{2}\left({ }^{-}\right.$, Gonzalo Hernández-Rodrigo ${ }^{2}$, Pedro Aguado ${ }^{2}$, \\ and Francisco Ayuga ${ }^{1}$
}

${ }^{1}$ BIPREE Research Group, ETSIAAB, Technical University of Madrid, Avda. Puerta de Hierro 2, 28040 Madrid, Spain

${ }^{2}$ Department of Engineering and Agricultural Sciences, University of Leon, Avda. de Portugal, 41, 24071 Leon, Spain

Received July 24, 2020; accepted November 11, 2020

\begin{abstract}
Wood pellets are increasingly being used to produce energy as a part of the decarbonization process of the economy, but their handling is associated with several problems, which usually requires that the equipment used has to be modified and improved. The discrete element method is a numerical technique suitable for simulating individual particles and handling systems. This paper focuses on the determination of the mechanical and physical parameters for wood pellet particles which are required to develop a discrete element method model to improve handling and transport systems. This study reports the experimentally determined values for wood pellet particles with respect to particle density, modulus of elasticity, particle - particle and particle - wall coefficients of restitution, and particle - particle and particle - wall coefficients of friction. Following the previous findings by other researchers with large samples of bulk material, it has been found that the modulus of elasticity for individual wood pellets depends on the water content, and the particle - wall coefficient of restitution depends on the impact velocity.

Keywords: biomass, wood pellets, mechanical properties, discrete element method
\end{abstract}

\section{INTRODUCTION}

Pellet production from different waste materials is an emerging sector that has gained a significant importance recently because of their use in the production of energy

\footnotetext{
*Corresponding author e-mail: eutiquio.gallego@upm.es

**This work was supported by the Spanish Research State Agency via the research project "Study of the structural behaviour of corrugated wall silos using Discrete Element Models (SILODEM)" (Grant No. PID2019-107051GB-I00 / AEI / 10.13039/501100011033, 2020 - 2023).
}

from renewable sources, this is among the topics included in the Circular Economy Action Plan approved by European Union (European Commission, 2019). The handling and storage operations for the wood pellets may lead to the appearance of several problems, e.g. wearing (Aarseth, 2004) or breakage (Oveisi et al., 2013). In these processes, the production of dust is one of the main consequences, which leads to an increase in the risk of an explosion taking place (Saeed et al., 2019) and a reduction in the effectiveness of forced ventilation techniques (Yazdanpanah et al., 2010).

The attrition and breakage of wood pellets and the dust generated during handling operations has increased the demand for improvements in the equipment and facilities used. Because of this, many experimental works or numerical simulations have been conducted in recent years. Jägers et al. (2020) analysed the effect of different operation conditions and pipe components on pellet degradation and dust appearance when using pneumatic conveyor processes. They determined the degree of influence of air flow or particle velocity in the aforementioned problems. Graham et al. (2017) investigated the influence of different storage conditions on several properties of wood pellets. Wood pellets stored outdoors may be subjected to freezing and defrosting processes, and they usually exhibit a higher moisture content, even if they are placed in roof-covered locations (Graham et al., 2017), because increased relative humidity

(C) 2020 Institute of Agrophysics, Polish Academy of Sciences (c) (1) (8) $\odot$ 
leads to an increase in the moisture content of the pellet (Deng et al, 2019). The increase in wood pellet moisture content reduces their durability and mechanical properties, e.g. the modulus of elasticity and flexural strength, increases in pellet attrition and dust content or decreases in bulk density (Deng et al., 2019; Graham et al., 2017).

Discrete element models (DEM) are the preferred numerical technique which is currently being used to study handling related problems for wood pellets, since individual particles can be modelled. Hlosta et al. (2020b) developed a DEM model to study the mixing processes in rotary drums in order to improve the homogenization of particles and to avoid segregation problems. Gilvari et al. (2020) simulated the breakage of individual pellets subjected to uniaxial and diametrical compression tests in order to study pellet breakage for seven different types of biomass pellets. Schott $e t$ al. (2016) developed a DEM model to simulate a durability test for pellets, thereby emphasizing that durability tests do not adequately reproduce realistic handling conditions at the industrial scale. Kruggel-Emden and Kacianauskas (2013) developed a DEM model to investigate the mixing and transport of particles in grate systems. The grate was operated periodically with cylindrical wood pellets being applied as bed material, while different motion patterns and grate operational conditions were analysed.

The development of numerical models requires the measurement and calculation of mechanical properties that must be obtained for the specific materials under consideration. Moreover, the DEM technique requires that mechanical properties are obtained for individual particles, but many granular materials usually exhibit a large discrepancy in those values when they are obtained for individual particles. For example, the particle-particle coefficient of friction can have a great influence on the simulation of grading systems (Kruggel-Emden and Kacianauskas, 2013). Because of this, sensitivity analyses of some input parameters of individual particles are usually conducted with DEM and combined with the experimental results to develop a numerical model that adequately reproduces the problem considered. Following this scheme, Hlosta et al. (2020a) combined the experimental results obtained from several apparatus with numerical simulations in order to validate the values of different interaction coefficients (i.e., the static friction coefficient, the rolling friction coefficient or the coefficient of restitution) required to develop a DEM model. Rozbroj et al. (2019) used DEM simulations to conduct a sensitivity analysis of the length accuracy grade of cylindrical pellets with the optimal calibration of time and velocity during the discharge of a cylindrical vessel.

With regards to wood pellets, some authors (Stasiak et al., 2019; Wu et al., 2011) have tested different raw materials in order to obtain some mechanical parameters, but they referred to a bulk mass and not to individual particles. Jezerska et al. (2018) determined many parameters with regard to the physical and mechanical properties of wood pellets, but they were not focused on the parameters required by DEM simulations. Hlosta et al. (2018) determined the particle - particle coefficient of restitution for several materials, including cylindrical spruce pellets.

The goal of this research work was to experimentally determine the values of the mechanical properties of wood pellets at the particle-scale required to develop DE models that can simulate handling equipment in order to improve its design. Besides, some of the mechanical parameters required by DEM models, e.g. the modulus of elasticity or coefficients of friction have not been obtained for wood pellet particles up to date.

\section{MATERIALS AND METHODS}

The materials used in the present study were pine wood pellets, supplied by Coterram Generation S.A. Table 1 shows the components of three different samples of wood pellets used for the tests, their parameters were tested by the supplier of the material. It may be confirmed that the combination of Carbon and Oxygen accounts for more than $93 \%$ of the wood pellet weight, as it was expected. In addition, it may be seen that the average bulk density is over $650 \mathrm{~kg} \mathrm{~m}^{-3}$, which is a significantly higher value than the one corresponding to other biomass products.

A sample of 100 pellets was selected to calculate their length, diameter and estimated volume. A micrometer was used to measure diameter and pellet length, while the volume was estimated by assuming a cylindrical shape for the pellet. The main results can be seen in Table 2, where it is observed that the average length is $17.70 \mathrm{~mm}$ with a coefficient of variation of $26.5 \%$. Because of the extrusion process used to produce the pellets, the average value of their diameter is very close to $6 \mathrm{~mm}$ and it exhibits a very low coefficient of variation. Figure 1 shows the distribution of the pellet volume obtained with the sample used, and it may be seen that there is quite a uniform distribution in the range $300-700 \mathrm{~mm}^{3}$.

Two different methodologies were used to determine the true density $\left(\rho_{p}\right)$ of the wood pellet particles. Method 1 consists of the direct measurement of the mass of each individual particle $\left(m_{i}\right)$, by using a precision balance with an accuracy of $0.01 \mathrm{~g}$. In addition, the length $\left(L_{i}\right)$ and diameter $\left(D_{i}\right)$ of each individual particle was measured to calculate its volume $\left(V_{i}\right)$, while assuming the existence of a cylindrical shape (Eq. (1)), thus the true density of each individual particle may be calculated through Eq. (2).

$$
\begin{gathered}
V_{i}=\frac{\pi}{4} L_{i} D_{i}^{2}, \\
\rho_{p}=\frac{m_{i}}{V_{i}} .
\end{gathered}
$$

Method 2 was based on the specifications defined in standard ISO 18847 (2016), and considered a sample of several pellets for each replica. The density of the particles which was calculated through Method 2 can also be obtained by 
Table 1. Composition of the wood pellets used in this research

\begin{tabular}{|c|c|c|c|c|}
\hline \multirow{2}{*}{ Parameter } & \multicolumn{3}{|c|}{ Sample } & \multirow{2}{*}{ Average value } \\
\hline & M1 & M2 & M3 & \\
\hline Moisture content $(\%)$ & 6.8 & 6.5 & 6.3 & 6.53 \\
\hline Volatiles (\%) & 83.5 & 83.7 & 83.4 & 83.53 \\
\hline Ash content $\left(815^{\circ} \mathrm{C}\right)(\%)$ & 0.36 & 0.40 & 0.40 & 0.39 \\
\hline Ash content $\left(550^{\circ} \mathrm{C}\right)(\%)$ & 0.58 & 0.48 & 0.46 & 0.51 \\
\hline Carbon $(\%)$ & 51.07 & 51.90 & 51.81 & 51.59 \\
\hline Hydrogen (\%) & 6.19 & 6.36 & 6.25 & 6.27 \\
\hline Nitrogen $(\%)$ & 0.03 & 0.08 & 0.06 & 0.06 \\
\hline Sulphur (\%) & 0.04 & 0.03 & 0.04 & 0.04 \\
\hline Chlorine (\%) & 0.013 & 0.007 & 0.012 & 0.01 \\
\hline Oxygen $(\%)$ & 42.30 & 41.22 & 41.43 & 41.65 \\
\hline Higher heating value $\left(\mathrm{kcal} \mathrm{kg}^{-1}\right)$ & 4889 & 5029 & 4970 & 4963 \\
\hline Lower heating value $\left(\mathrm{kcal} \mathrm{kg}^{-1}\right)$ & 4570 & 4706 & 4652 & 4643 \\
\hline Bulk density without compaction $\left(\mathrm{kg} \mathrm{l}^{-1}\right)$ & 0.66 & 0.63 & 0.69 & 0.66 \\
\hline Bulk density with compaction $\left(\mathrm{kg} \mathrm{l}^{-1}\right)$ & 0.71 & 0.67 & 0.73 & 0.71 \\
\hline
\end{tabular}

All values refer to the dry mass of the sample, with the exception of the moisture content and bulk density.

Table 2. Pellet dimensions

\begin{tabular}{|c|c|c|c|c|c|}
\hline \multirow{2}{*}{ Parameter } & \multirow{2}{*}{ Average } & \multicolumn{2}{|c|}{ Value } & \multirow{2}{*}{$\begin{array}{l}\text { Standard } \\
\text { deviation }\end{array}$} & \multirow{2}{*}{$\begin{array}{c}\text { Coefficient } \\
\text { of variation }(\%)\end{array}$} \\
\hline & & $\max$ & $\min$ & & \\
\hline Length $\left(L_{i}, \mathrm{~mm}\right)$ & 17.70 & 27.98 & 8.33 & 4.70 & 26.50 \\
\hline Diameter $\left(D_{i}, \mathrm{~mm}\right)$ & 6.08 & 6.21 & 5.96 & 0.05 & 0.90 \\
\hline Volume $\left(V_{i}, \mathrm{~mm}^{3}\right)$ & 513.5 & 799.0 & 244.2 & 135.1 & 26.3 \\
\hline
\end{tabular}

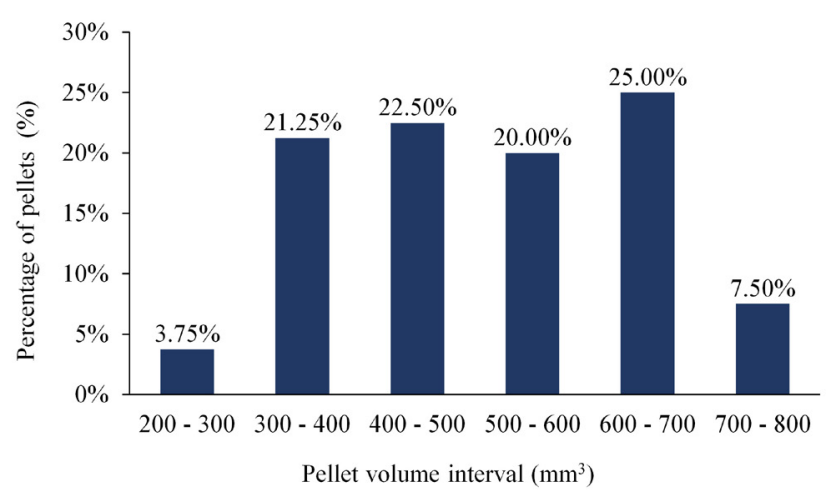

Fig. 1. Classification of the wood pellets used in this research according to their volume.

using Eq. (2). In this case, $V_{i}$ is the volume of water displaced by the pellet sample, and $\mathrm{m}_{\mathrm{i}}$ is the mass of pellets tested. The measurement of the properties for a sample of 20 wood pellets was used for Method 1, while five samples weighing 35-40 g of wood pellets (approximately 50-60 units) were randomly selected in order to apply Method 2.
The modulus of elasticity for a material, also known as Young's modulus, is a mechanical parameter that characterizes its rigidity. It is calculated as the ratio between the tension suffered by the material in a particular direction and the unit deformation obtained in that direction. This mechanical parameter is widely determined for the bulk mass of any type of granular product by using standard procedures such as direct shear or triaxial tests (Molenda et al., 2006; Moya et al., 2002).

The procedures required to determine the modulus of elasticity for individual particles are not widely known. Therefore, the method described in standard ASAE 368.4 (2006) is the procedure that is usually employed (Ramírez et al., 2014; González-Montellano et al., 2012), it is based on the Hertz theory for contact stresses by employing the data obtained in a compression test carried out for an individual particle. The compression tests were carried out in this research by using a XT2 Texture Analyser (Stable Micro System Ltd., Gloaming, UK) equipped with a load cell of $250 \mathrm{~N}$ with a $3.18 \mathrm{~mm}$-diameter spherical compression tool. 
In order to determine the modulus of elasticity, the 'Type D' compression test as defined in ASAE 368.4 (2006) was performed: spherical indenter in contact with a flat surface. The speed of testing was $0.1 \mathrm{~mm} \mathrm{~s}^{-1}$, and a forcedeformation curve was obtained for each particle tested in order to determine the point of inflection, the level of force $(F, \mathrm{~N})$ and deformation $(D, \mathrm{~mm})$ were registered in order to calculate Young's modulus $\left(E_{p}\right)$ for the wood pellets tested by using Eq. (3):

$$
E_{p}=\frac{0.338 F\left(1-v^{2}\right)}{D^{1.5}} K_{U}^{1.5}\left(\frac{4}{d}\right)^{0.5},
$$

where: $F$ is the compression force applied to the sample at the point of inflection, $D$ is the deformation measured at the point of inflection, $v$ is the Poisson coefficient of the material, $d$ is the diameter of the spherical compression tool. In agreement with the recommendations and explanations provided in standard ASAE 368.4 (2006), a constant value $K_{U}=1.351$ was selected for the test type conducted and the existence of a Poisson coefficient of $v=0.4$ was assumed for the wood pellets, which can also be used to obtain the shear modulus $G$ (Eq. (4)):

$$
G=\frac{E}{2(1-v)}
$$

One of the objectives of this research work was to assess the influence of percentage humidity on the modulus of elasticity for individual wood pellets. Therefore, 4 different water contents were tested: $2.5,5,10$ and $15 \%$. The determination of pellet moisture content, when required for tests, was made following the procedure outlined in ISO 18134-2 (2017). A sample of wood pellets containing 40-50 individual dried particles was weighed, and the water required to reach the desired moisture content was added to them and gently mixed in a dry capsule. After that, the humidified wood pellets were transferred to a second dry capsule to ensure that the final weight matched the expected values. This process was repeated until the desired moisture content was obtained, thereby ensuring an appropriate distribution of water. Compression tests were conducted immediately after a particular moisture content was reached; this was set to avoid any loss of humidity and degradation of the particles. Other procedures were not included since it was observed that they induced an excessive level of deterioration of the wood pellets, especially for high water contents. A final number of 20-25 wood pellets were tested for every percentage humidity. The humidity content of wood pellets tested to determine the other parameters was $2.5 \%$, this was achieved after drying the pellets and storing them in "indoor" conditions, then allowing them to absorb some moisture from the ambient conditions. This procedure was an attempt to reproduce the conditions of real storage "indoors".
The coefficient of restitution reflects the quantity of energy lost during the collision between two objects. If the collision involves two particles, then the particle-particle coefficient of restitution $\left(e_{p}\right)$ is obtained. If one object is a particle, and the second one is a wall sample, then the particle-wall coefficient of restitution $\left(e_{w}\right)$ is obtained. Bedford and Fowler (2008) showed that the coefficient of restitution may be obtained from Eq. (5) if the objects involved in the collision are not subjected to rotation, and both wood pellets have similar dimensions, therefore they have similar masses. Subscripts 1 and 2 refer to the objects involved in the collision, while $u$ and $v$ represent the velocity of the objects just before and after the collision, respectively:

$$
e=-\frac{v_{2}-v_{1}}{u_{1}-u_{2}} \text {. }
$$

The determination of $e_{p}$ was based on the procedure described by Hlosta et al. (2018), where a double pendulum test was built to allow for collisions between two wood pellets in contact. The pendulum strings used have a similar length and are made from cotton fibres. Each string is glued to one wood pellet following an axial direction to obtain a perfectly stable particle, with no inclination with respect to the horizontal axis and perfect alignment with respect to the other wood pellet. Also, a high speed camera recording $240 \mathrm{fps}$ was used to monitor the complete trajectory of both pellets for every instant of the test.

One of the particles - Particle A - is laterally displaced to a height $h_{A, 1}$ with respect to the position of Particle B, and forms an initial angle of inclination with respect to the vertical axis, $\alpha_{A 1}$. After that instant, Particle $\mathrm{A}$ is released and impacts against Particle $\mathrm{B}$, which reaches a final height $h_{B, 2}$ with respect to its initial position, and forms a final angle of inclination with respect to the vertical axis, $\alpha_{B 2}$. As explained by Hlosta et al. (2020a), the particle - particle coefficient of restitution may be obtained by using Eq. (6) or Eq. (7). Five samples of each material were tested, involving three different initial heights $h_{A 1}: 195,100$, and $55 \mathrm{~mm}$. The number or replicas for each sample ranged between 10 and 15 :

$$
\begin{gathered}
e_{p, 1}=\sqrt{\frac{h_{B 2}}{h_{A 1}}}, \\
e_{p, 2}=\sqrt{\frac{1-\cos \alpha_{B 2}}{1-\cos \alpha_{A 1}}} .
\end{gathered}
$$

The particle-wall coefficient of restitution was obtained by using drop tests similar to those described by RamírezGomez et al. (2014) and Gonzalez-Montellano et al. (2012). A wood pellet is released from an initial height $\left(h_{0}\right)$, above the flat wall surface used, and bounces to a maximum height $\left(h_{1}\right)$, (lower than $h_{0}$ ) after its impact with the wall. The number of replicas required was very large in order to ensure the absence of rotations or lateral displacements 
after the collisions had taken place. Thus, many drop tests had to be discounted since they did not accomplish these conditions. A sample of steel wall was used to determine the particle-wall coefficient of restitution. A high-speed camera (240 fps) was used to record the particle drop and capture the height of bounce of the wood pellet.

Velocities $v_{2}$ and $u_{2}$ (Eq. (5)) corresponding to the flat steel surface were zero, and it was hypothesized that energy conservation was maintained both before and after the impact of the wood pellet. Thus, the coefficient of the restitution particle-wall $\left(e_{w}\right)$, may be calculated as a function of the previously defined heights $h_{0}$ and $h_{1}$ (Eq. (8)). Five pellet samples were tested, starting at three different release heights $\left(h_{0}\right)$, with at least 10 valid replicas for each pellet sample and height (with a total of over 150 assays):

$$
e_{w}=-\frac{v_{1}}{u_{1}}=\sqrt{\frac{h_{1}}{h_{0}}} .
$$

The coefficient of friction reflects the resistance of two objects in contact which are also in motion sliding against each other. At a particle level, it is possible to determine the particle - particle $\left(\mu_{p}\right)$ or particle - wall $\left(\mu_{w}\right)$ coefficients of friction. Some 3 different material samples and $10-15$ replicates for each sample were considered in order to determine both coefficients of friction. The value of $\mu_{w}$ was determined by using an inclined plane and following the procedure of a sliding assay previously used (RamírezGomez et al., 2014). Three individual wood pellets are glued to a wood panel and placed in contact with the steel wall sample, which was fixed to the inclined plane. Then, the inclined plane is progressively raised at a constant speed until the particles begin to slide when the platform reaches an angle of inclination $\alpha_{d}$. Therefore, the particle wall coefficient of friction may be obtained through Eq. (9):

$$
\mu_{w}=\tan \alpha_{d} .
$$

The determination of the particle - particle coefficient of friction is complex because it is difficult to implement any procedure which allows for an appropriate simulation of this phenomenon, and few works describe it (O'Sullivan et al., 2004). The authors have developed an alternative system based on the previously described inclined plane. In this case, the wall sample plate is replaced by another plate that has three sets of wood pellets glued to it, matching the location of the three individual wood pellets placed at the sliding plate. In this case, the test procedure is the same, however, the angle of inclination of the platform reached $\left(\alpha_{p}\right)$ allows for the determination of the particle - particle coefficient of friction (Eq. (10)):

$$
\mu_{p}=\tan \alpha_{p} .
$$

Box plots and the Grubbs test, which assumes a normal distribution of results, were used for all of the tests conducted in order to detect atypical observations, these were removed from the analyses before calculating any of the wood pellet properties. Because of this, the final number of wood particles mentioned in section 4 of the paper may be less than the initial number of wood pellets tested (and indicated in section 2 of the paper for each test type). The main statistics parameters (mean, standard deviation and Coefficient of variation) were determined for all of the wood pellet properties tested. Also, $95 \%$ confidence intervals $(95 \% \mathrm{CI})$ were obtained from the distributions of the results and the calculated means and standard deviations.

For the determination of wood pellet density, the mean results of Methods 1 and 2 were compared using the Student $t$ test. The variances of the results provided by each method were compared using the Fisher F-test. Simple regression models were built to correlate specific mechanical properties with some parameters, e.g. the percentage water content or the impact velocity of the wood pellet. The choice of a particular regression line was made using the results considered in each case for maximizing the value of the coefficient of determination $\left(\mathrm{R}^{2}\right)$.

A $95 \%$ level of confidence $(\alpha=0.05)$ was set for all of the statistical tests conducted, this is considered to be appropriate for the material parameters analysed. In addition, it was confirmed for all of the tests conducted that the number of repetitions made was sufficient to obtain a representative average value, by considering a $95 \%$ confidence level and estimating an error of $15 \%$ (adequate for all types of agricultural and raw materials that usually exhibit a large degree of heterogeneity).

\section{RESULTS AND DISCUSSION}

Table 3 shows the results obtained for the calculation of wood pellet density for both methods. For both methods tested, no atypical results were found and the hypothesis of the existence of a normal distribution could not be discounted. It is interesting to note that Method 1 provides a slightly greater mean pellet density than Method 2 (1247 and $1227 \mathrm{~kg} \mathrm{~m}^{-3}$, respectively). The values obtained using

Table 3. Density of wood pellet particles $\left(\sigma_{p}\right)$

\begin{tabular}{lcc}
\hline Parameter & Method 1 & Method 2 \\
\hline Mean $\left(\mathrm{m}, \mathrm{kg} \mathrm{m}^{-3}\right)$ & 1247 & 1227 \\
Standard deviation $\left(\sigma, \mathrm{kg} \mathrm{m}^{-3}\right)$ & 36.85 & 18.02 \\
Coefficient of variation $(\mathrm{CV}, \%)$ & 2.96 & 1.47 \\
$95 \%$ confidence interval $\left(\mathrm{CI}, \mathrm{kg} \mathrm{m}^{-3}\right)$ & {$[1227-1267]$} & {$[1205-1249]$} \\
\hline
\end{tabular}


both methods are in agreement with those reported by other authors. Dyjakon and Noszczyk (2019) determined a particle density of $1385 \mathrm{~kg} \mathrm{~m}^{-3}$ for pine sawdust pellets, while Frodeson et al. (2019) obtained an approximate density value of $1100 \mathrm{~kg} \mathrm{~m}^{-3}$ for pine wood raw material and also the humidity content of the pellets tested in this research. Jezerska et al. (2018) obtained a pellet density of around $1350 \mathrm{~kg} \mathrm{~m}^{-3}$.

A Student t-test was conducted to check if this difference between the two methods would be statistically significant. A p-value of $0.065(\mathrm{p}>\alpha)$ was found, therefore no significant differences were found between the two methods. This can be explained by the regularity in the shape of the wood pellets. However, it seems that it would be preferable to use Method 2 because the coefficient of variation obtained is slightly lower ( $1.47 \%$ against $2.96 \%$ ), and it is also a shorter procedure.

Table 4 shows the results obtained for the value of the modulus of elasticity obtained for each percentage humidity considered. The number of wood pellets (n) included in Table 4 is lower than the initial number of wood pellets tested (and defined in section 2) because the atypical values detected by applying Grubbs test were removed from the statistical analysis. The number of atypical values increases with higher water contents, because wood pellets degrade to a significant extent when the water content is high, and then a greater difference between the particles tested also appears.

The highest mean modulus of elasticity $(73.33 \mathrm{MPa})$ is obtained for the sample with the lower humidity content $(\mathrm{w}=2.5 \%)$, while the lowest mean modulus of elasticity (14.14 MPa) corresponds to the sample with the greatest humidity content $(\mathrm{w}=15 \%)$. The coefficient of variation obtained for all percentage humidity values lies in the range $25-40 \%$, which is a value consistent with the results obtained for other products and raw materials (Ramírez et al., 2014; González-Montellano et al, 2012).

There are few studies in the literature reporting values for the modulus of elasticity of wood pellets (Graham et al., 2017; Kocsis and Csanády, 2017). Kocsis and Csanády (2017) measured the modulus of elasticity during the formation of individual pellets through a compression channel with the diameter of the final pellet. For a wood pellet with a diameter similar to the one tested in this research $(\phi=6 \mathrm{~mm})$, they found a modulus of elasticity in the compressed pellet of 146 and $221 \mathrm{MPa}$ for spruce (Picea abies) and black locust (Robinia pseudoacacia) origins. These values are greater than the ones obtained in this research, but no direct comparison can be made because the raw material used is different: pine instead of spruce or black locust. In addition, the testing apparatus used by Kocsis and Csanády (2017) determined the modulus of elasticity for a completely confined material in the compression channel, while compression loads are directly applied over the wood pellet with no lateral constraint at any point, according to the procedure used in this research.

Graham et al. (2017) also reported values for the modulus of elasticity in the range $187-322 \mathrm{MPa}$ for materials stored indoors. In this case, the raw material studied is the same one (pine), but the modulus of elasticity was not determined for individual wood pellets. They employed raw wood of dimensions $50 \times 50 \mathrm{~mm}$ for compression tests, thus employing a large number of wood pellets simultaneously. The results obtained for the axial modulus of elasticity suggests a close dependence on the moisture content (Fig. 2). Thus, Student t-tests were conducted between the results for the different water contents (w, \%), and statistically significant differences were found for all contents. Because of this, a linear regression analysis (Eq. (11)) was tested between the modulus of elasticity and water content, and a very close relationship $\left(R^{2}=0.94\right)$ was found. Figure 2 shows the average value and the standard deviation of the modulus of elasticity for each water content, as well as the correlation equation between the two parameters. Therefore, it is clearly apparent that the modulus of elasticity tends to decrease with increasing moisture contents, according to Eq. (11) and for the humidity content interval tested (2.5-15\%):

$$
E(\mathrm{MPa})=77.99-4.38 w(\%)\left(\mathrm{R}^{2}=0.94\right) .
$$

Table 5 shows the results obtained for the particle - particle coefficient of restitution obtained from the 5 samples (S1 to S5) of wood pellets tested, by considering the 3 initial dropping heights $\left(h_{\mathrm{A} 1}, h_{\mathrm{A} 2}\right.$ and $\left.h_{\mathrm{A} 3}\right)$ and calculating $e_{p, 1}$ and $e_{p, 2}$ according to Eq. (6) and (7). In addition, Fig. 3 shows the coefficient of restitution calculated according to method $1\left(e_{p, 1}\right)$ for every sample and the mean value for

Table 4. Modulus of elasticity of wood pellet particles $\left(E_{p}\right)$ for different water contents (w, \%)

\begin{tabular}{lcccc}
\hline \multirow{2}{*}{ Parameter } & \multicolumn{4}{c}{ Water content (w, \%) } \\
\cline { 2 - 5 } & 2.5 & 5.0 & 10.0 & 15.0 \\
\hline Mean $(\mathrm{m}, \mathrm{MPa})$ & 73.33 & 48.50 & 33.64 & 14.14 \\
Standard deviation $(\sigma, \mathrm{MPa})$ & 25.43 & 12.36 & 9.22 & 6.10 \\
Coefficient of variation $(\mathrm{CV}, \%)$ & 34.68 & 25.48 & 27.42 & 43.11 \\
Number of samples $(\mathrm{n})$ & 21 & 19 & 19 & 17 \\
$95 \%$ confidence interval $\left(\mathrm{CI}, \mathrm{kg} \mathrm{m}^{-3}\right)$ & {$[61.76-84.90]$} & {$[42.54-54.46]$} & {$[29.20-38.09]$} & {$[10.62-17.66]$} \\
\hline
\end{tabular}




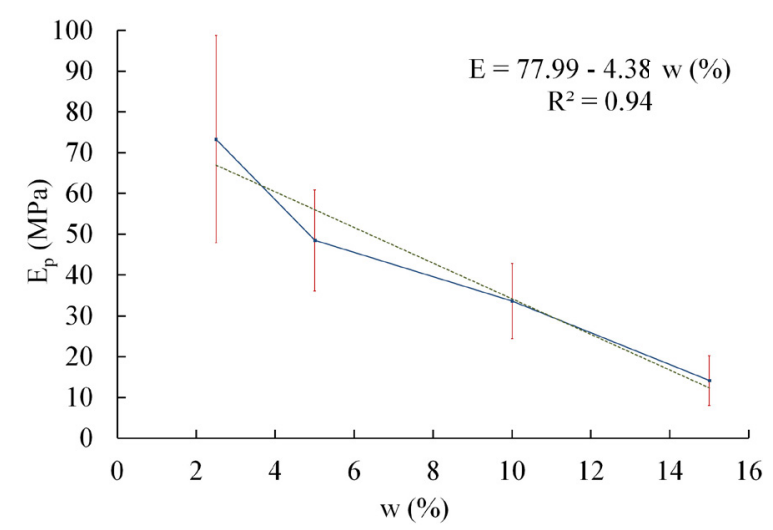

Fig. 2. Modulus of elasticity of wood pellet particles $\left(E_{p}\right)$ as a function of water content percentage $(\mathrm{w}, \%)$. is quite similar to the one (0.69) reported by Hlosta et al. (2018) for cylindrical spruce pellets when calculating the coefficient with the particle height variable.

The regular shape of the material explains the low Coefficient of variation found (less than $12 \%$ for all cases), which is indicative of the repeatability of the test for this material and particle shape. Different statistical Student t-tests were conducted for every dropping height and for both methods of calculating the coefficient. For the highest dropping height $\left(h_{A 1}=195 \mathrm{~mm}\right)$, no significant differences were found between the two methods of calculating the particle - particle coefficient of restitution. However, significant statistical differences $(\mathrm{p}<0.05=\alpha)$ were obtained for the other dropping heights, despite the difference between the average values for both methods being less than $10 \%$.

Table 5. Particle - particle coefficient of restitution $\left(e_{p}\right)$ obtained for 3 different dropping heights $\left(h_{A i}\right)$

\begin{tabular}{lcccccc}
\hline \multirow{2}{*}{ Parameter } & \multicolumn{2}{c}{$h_{A 1}=195 \mathrm{~mm}$} & \multicolumn{2}{c}{$h_{A 2}=100 \mathrm{~mm}$} & \multicolumn{2}{c}{$h_{A 3}=55 \mathrm{~mm}$} \\
\cline { 2 - 7 } & $e_{p, 1}$ & $e_{p, 2}$ & $e_{p, 1}$ & $e_{p, 2}$ & $e_{p, 1}$ & $e_{p, 2}$ \\
\hline Mean $(\mathrm{m})$ & 0.61 & 0.60 & 0.64 & 0.61 & 0.61 & 0.56 \\
Standard deviation $(\sigma)$ & 0.051 & 0.051 & 0.052 & 0.049 & 0.072 & 0.076 \\
Coefficient of variation (CV, \%) & 8.3 & 8.6 & 8.1 & 8.1 & 11.8 & 5 \\
Number of particles (n) & 5 & 5 & 5 & 5 & 5.5 & 5 \\
95\% confidence interval (CI) & {$[0.60-0.64]$} & {$[0.59-0.62]$} & {$[0.62-0.66]$} & {$[0.59-0.62]$} & {$[0.59-0.64]$} & {$[0.54-0.59]$} \\
\hline
\end{tabular}

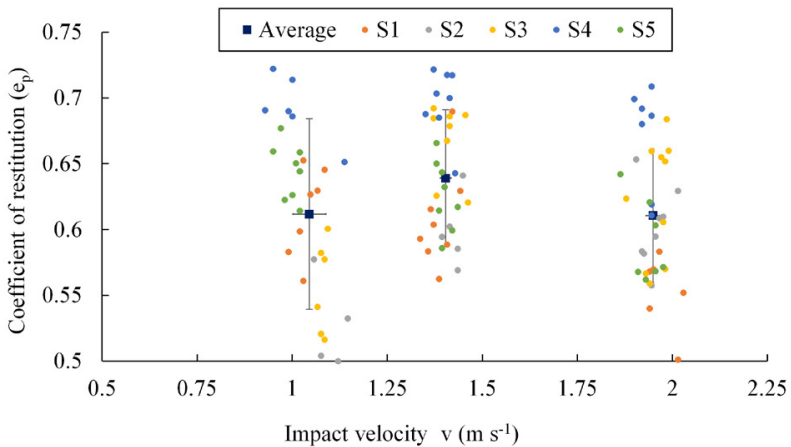

Fig. 3. Particle - particle coefficient of restitution $\left(e_{p}\right)$ for wood pellet particles as a function of impact velocity $\left(v, \mathrm{~m} \mathrm{~s}^{-1}\right)$.

each dropping height. It may be observed that the results are represented with regard to the impact speed, which was obtained through Eq. (12):

$$
v=\sqrt{2 g h_{A}} .
$$

The particle - particle coefficient of restitution for wood pellets lies in the range $0.60-0.64$ for any dropping height and method of calculation used, with the exception of the value for method 2 and a dropping height $h_{A 3}=55 \mathrm{~mm}$ (0.56). The different dropping heights do not appear to influence the value of the coefficient of restitution (Fig. 3), which is a finding that was also observed by Gonzalez -Montellano et al. (2012) for some materials. This value
This discrepancy can be explained by the errors attributed to the experimental procedure which have a greater degree of influence for low dropping heights. This finding can be corroborated by the fact that the Coefficient of variation is lower for greater dropping heights. Therefore, it is recommended that the dropping height should be greater than $100 \mathrm{~mm}$ to obtain a more representative value of this coefficient, taking into account that the dropping height does not affect its value.

Table 6 shows the results obtained for each of the three initial heights, $\mathrm{H}_{0}$, considered in the tests. The coefficient of variation ranged between 11 and $15 \%$ for all heights, and it is greater than those obtained by Gonzalez - Montellano et al. (2012) for spherical glass beads. The cylindrical shape of the particle tested made them bounce in non-vertical directions for many repetitions, thereby providing them with a rotational velocity that would invalidate the test. Thus, it was necessary to perform a large number of replicas in order to obtain 10 vertical bounces, at least, for each of the five samples tested. This is the reason why the coefficient of variation is slightly greater than that observed for a spherical shape.

It may be confirmed that the particle-wall coefficient of restitution decreases when the impact velocity increases (Fig. 4), this occurs for increasing release heights, $\mathrm{H}_{0}$. The results obtained for wood pellets could not be compared with those in other published papers. However, the 
Table 6. Particle - wall coefficient of restitution $\left(e_{w}\right)$ obtained for 3 different dropping heights

\begin{tabular}{lccc}
\hline Parameter & $\mathrm{H}_{0}=250 \mathrm{~mm}$ & $\mathrm{H}_{0}=150 \mathrm{~mm}$ & $\mathrm{H}_{0}=50 \mathrm{~mm}$ \\
\hline Mean $(\mathrm{m})$ & 0.47 & 0.49 & 0.51 \\
Standard deviation $(\sigma)$ & 0.068 & 0.064 & 0.057 \\
Number of samples $(\mathrm{n})$ & 5 & 5 & 5 \\
Coefficient of variation $(\mathrm{CV}, \%)$ & 14.5 & 13.2 & 11.3 \\
$95 \%$ confidence interval $(\mathrm{CI})$ & {$[0.45-0.48]$} & {$[0.47-0.51]$} & {$[0.49-0.52]$} \\
\hline
\end{tabular}

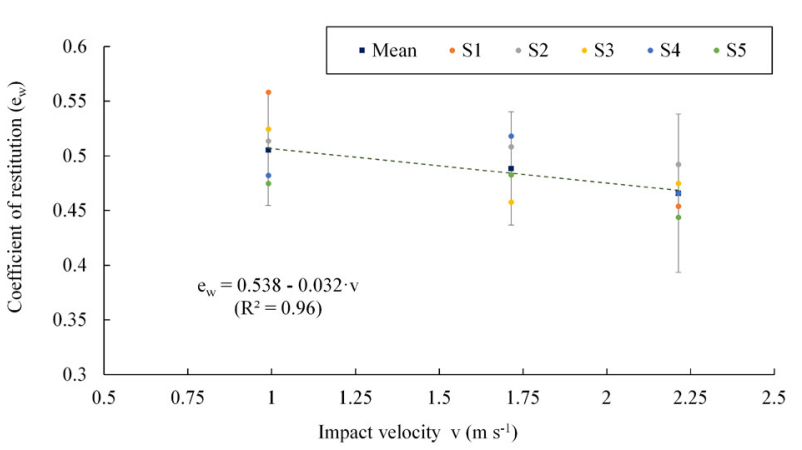

Fig. 4. Particle - wall coefficient of restitution $\left(e_{w}\right)$ for wood pellet particles as a function of impact velocity $\left(v, \mathrm{~m} \mathrm{~s}^{-1}\right)$.

overall trend of the results may also be found in other studies designed to determine the particle-wall coefficient of restitution (Wojtkowski et al., 2010; Wong et al., 2009). Hastie (2013) obtained the particle-wall coefficient of restitution for irregular particle shapes, including polyethylene cylindrical pellets. The average value of the coefficient of restitution found by Hastie (2013) against a stainless steel wall was 0.53 for a $0.3 \mathrm{~m}$ release height. This value is slightly greater than the one obtained in this research $(0.47)$ for a dropping height of $0.25 \mathrm{~m}$, but the differences can be explained by the different nature of the material tested. In addition, Hastie (2013) also observed a decrease in the coefficient of restitution for increasing release heights.

Statistical Student t-tests were conducted for all combinations of dropping heights to check if the differences found for the particle - wall coefficient of restitution were significant. Indeed, significant differences were found between the release height $h_{0}=0.25 \mathrm{~m}$ and the release heights $h_{0}=0.15 \mathrm{~m}$ and $h_{0}=0.05 \mathrm{~m}$, because for both t-tests the p-values obtained $(0.039$ and 0.001$)$ were lower than the significance level $(\alpha=0.05)$. Because of this, a linear regression model was constructed to take into account the speed of impact and the restitution coefficient (Eq. (13)). A very high degree of correlation between both variables was found $\left(R^{2}=0.96\right)$, this was to be expected because of the results of the previous t-tests conducted.

$$
e_{w}=0.538-0.032 v\left(\mathrm{~m} \mathrm{~s}^{-1}\right) \quad\left(\mathrm{R}^{2}=0.96\right) .
$$

Table 7 shows the coefficients of friction obtained for particle - wall and particle - particle. No atypical values were detected for any parameter, repetition or sample. The coefficient of variation for both parameters is lower than $15 \%$, thereby indicating the favourable repeatability of the tests conducted, and the representativeness of results. There are no published results for these coefficients in the literature with regard to wood pellets.

Stasiak et al. (2019) and Wu et al. (2011) published values for the angle of internal friction for wood pellets. Their results cannot be directly compared with the results obtained in this research because their tests were not similar, and both works considered a bulk mass of wood pellets, instead of individual particles. Eq. (14) may be used to calculate the friction angle obtained between two wood pellets in contact $\left(\varphi_{p}\right)$. This value does not represent the angle of internal friction of the material, but it provides a reasonable estimation of it. Thus, the real angle of internal friction of the material and the value calculated according to Eq. (14) should be close:

$$
\phi_{p}=\operatorname{atan} \mu_{p}
$$

Stasiak et al. (2019) found that the angle of internal friction could vary between 26.8 and $30.2^{\circ}$ depending on the normal pressure applied during the development of a Jenike shear test. Therefore, it may be seen that the mean value obtained in this research work $\left(26.2^{\circ}\right)$ is in agreement with those reported by Stasiak et al. (2019). Wu et al. (2011) conducted shear tests on a large - scale annular apparatus

Table 7. Particle - particle $\left(\mu_{p}\right)$ and particle - wall $\left(\mu_{w}\right)$ coefficients of friction and the corresponding angles of friction $\left(\varphi_{p}\right.$ and $\left.\varphi_{w}\right)$

\begin{tabular}{lcccc}
\hline \multirow{2}{*}{ Parameter } & \multicolumn{2}{c}{ Particle - particle } & \multicolumn{2}{c}{ Particle - wall } \\
\cline { 2 - 5 } & $\mu_{p}$ & $\varphi_{p}\left({ }^{(}\right)$ & $\mu_{w}$ & $\varphi_{w}\left({ }^{\circ}\right)$ \\
\hline Mean $(\mathrm{m})$ & 0.49 & 26.21 & 0.34 & 18.62 \\
Standard deviation $(\sigma)$ & 0.07 & 3.24 & 0.05 & 2.59 \\
Coefficient of variation $(\mathrm{CV}, \%)$ & 14.1 & 12.4 & 15.1 & 13.9 \\
Number of samples (n) & 3 & 3 & 3 & 3 \\
\hline
\end{tabular}


Table 8. Mean values and standard deviation for the mechanical parameters tested for wood pellets

\begin{tabular}{|c|c|c|}
\hline Parameter & Mean value & Standard deviation \\
\hline Particle density $\left(\rho_{p}, \mathrm{~kg} \mathrm{~m}^{-3}\right)$ & 1227 & 18.02 \\
\hline \multirow{2}{*}{ Modulus of elasticity $\left(E_{p}, \mathrm{MPa}\right)$} & $73.33(\mathrm{w}=2.5 \%)$ & $25.43(\mathrm{w}=2.5 \%)$ \\
\hline & \multicolumn{2}{|c|}{$\left[E_{p}(\mathrm{MPa})=77.99-4.38 \mathrm{w}(\%)\left(\mathrm{R}^{2}=0.94\right)\right]$} \\
\hline Particle - particle coefficient of restitution $\left(e_{p}\right)$ & 0.62 & 0.058 \\
\hline \multirow{2}{*}{ Particle - wall coefficient of restitution $\left(e_{w}\right)$} & 0.49 & 0.063 \\
\hline & \multicolumn{2}{|c|}{$\left[e_{w}=0.538-0.032 v\left(\mathrm{~m} \mathrm{~s}^{-1}\right)\left(\mathrm{R}^{2}=0.96\right)\right]$} \\
\hline Particle - particle coefficient of friction $\left(\mu_{p}\right)$ & 0.49 & 0.07 \\
\hline Particle - wall coefficient of friction $\left(\mu_{w}\right)$ & 0.34 & 0.05 \\
\hline
\end{tabular}

in order to determine the angle of internal friction, and they found that this parameter would vary between 33 and $43^{\circ}$ for wood pellets, these values were greater than those obtained in this research. Wu et al. (2011) also conducted many tests to determine the angle of friction $\left(\varphi_{w}\right)$ between wood pellets and different wall materials. They found a mean value of between 18 and $19^{\circ}$ for steel walls (depending on the characteristics of the steel wall), which is a very similar value to the one obtained in our research tests $\left(\varphi_{w}=\right.$ $\left.18.62^{\circ}\right)$. In addition, the coefficient of variation obtained by Wu et al. (2011) for their tests was $11.1 \%$, which is similar to the one obtained in this research. Salehi et al. (2019) also determined a wall friction angle between pine wood chips and steel walls in the interval of $16-19^{\circ}$. The properties of the material are not the same, but again the reported value is in agreement with the one obtained in this research study. Table 8 summarizes the mean values of the mechanical parameters determined in this work.

\section{CONCLUSIONS}

1. With regard to wood pellets, many of the parameters required to develop a discrete element method model had not been previously determined for individual particles, e.g. the modulus of elasticity, the particle - wall coefficient of restitution or the particle - particle and particle - wall coefficients of friction.

2. It has been confirmed the particle - wall coefficient of restitution has a very close correlation $\left(\mathrm{R}^{2}=0.96\right)$ with the impact velocity (related to the height of drop) of the wood pellet particle.

3. It has also been found that the longitudinal modulus of elasticity of wood pellets decreases significantly with the increasing moisture content of the wood pellet, since a very substantial coefficient of correlation has been found $\left(\mathrm{R}^{2}=0.94\right)$.

4. The mechanical properties of the wood pellets obtained in this paper may be used as input values to develop the discrete element method models used to simulate handling systems, e.g. screw feeders or conveyors. The simulations of these items of equipment can be used to prevent problems appearing during the handling of wood pellet particles such as blockages or excessive attrition.

\section{ACKNOWLEDGEMENTS}

The authors thank COTERRAM for providing the wood pellets required to conduct the tests. The authors also thank the research group "LPF-TAGRALIA", from the Technical University of Madrid, for having offered the XT2 Texture Analyzer used in this work.

Conflict of interest: The authors declare no conflict of interest.

\section{REFERENCES}

Aarseth K.A., 2004. Attrition of feed pellets during pneumatic conveying: the influence of velocity and bend radius. Biosystems Eng., 89(2), 197-213. https://doi.org/10.1016/j.biosystemseng.2004.06.008

ASAE S368.4, 2006. Compression Test of Food Materials of Convex Shape. American Society of Agricultural and Biological Engineers (ASABE).

Bedford A. and Fowler W., 2008. Engineering mechanics statics \& dynamics. Prentice Hall.

Deng T., Alzahrani A., and Bradley M., 2019. Influences of environmental humidity on physical properties and attrition of wood pellets. Fuel Processing Technol., 185, 126-138. https://doi.org/10.1016/j.fuproc.2018.12.010

Dyjakon A. and Noszczyk T., 2019. The influence of freezing temperature storage on the mechanical durability of commercial pellets from biomass. Energies, 12, 2627. https://doi.org/10.3390/en12132627

European Commission, 2019. Report from the Commission to the European Parliament, the Council, the European Economic and Social Committee and the Committee of the Regions on the implementation of the Circular Economy Action Plan. European Commission, Brussels. https://doi.org/10.1080/13880290902938435

Frodeson S., Henriksson G., and Berghel J., 2019. Effects of moisture content during densification of biomass pellets, focusing on polysaccharide substances. Biomass Bioenergy, 122, 322-330. https://doi.org/10.1016/j.biombioe.2019.01.048 
Gilvari H., de Jong W., and Schott D.L., 2020. Breakage behavior of biomass pellets: an experimental and numerical study. Computational Particle Mechanics. https://doi.org/10.1007/ s40571-020-00352-3

González-Montellano C., Fuentes J.M., Ayuga-Téllez E., and Ayuga F., 2012. Determination of the mechanical properties of maize grains and olives required for use in DEM simulations. J. Food Eng., 111(4), 553-562. https://doi.org/10.1016/j.jfoodeng.2012.03.017

Graham S., Eastwick C., Snape C., and Quick W., 2017. Mechanical degradation of biomass wood pellets during long term stockpile storage. Fuel Proc. Technol., 160, 143 -151. https://doi.org/10.1016/j.fuproc.2017.02.017

Hastie D.B., 2013. Experimental measurement of the coefficient of restitution of irregular shaped particles impacting on horizontal surfaces. Chemical Engineering Science, 101, 828-836. https://doi.org/10.1016/j.ces.2013.07.010

Hlosta J., Žurovec D., Rozbroj J., Ramírez-Gómez A., Nečas J., and Zegzulka J., 2018. Experimental dete.rmination of particle-particle restitution coefficient via double pendulum method. Chemical Eng. Res. Design, 135, 222-233. https:// doi.org/10.1016/j.cherd.2018.05.016

Hlosta J., Jezerská L., Rozbroj J., Žurovec D., Nečas J., and Zegzulka J., 2020a. DEM investigation of the influence of particulate properties and operating conditions on the mixing process in rotary drums: Part 1 Determination of the DEM Parameters and Calibration Process. Processes, 8, 222. https://doi.org/10.3390/pr8020222

Hlosta J., Jezerská L., Rozbroj J., Žurovec D., Nečas J., and Zegzulka J., 2020b. DEM Investigation of the influence of particulate properties and operating conditions on the mixing process in rotary drums: Part 2 - Process validation and experimental study. Processes, 8, 184. https://doi.org/10.3390/pr8020184

ISO 18134-2, 2017. Solid biofuels - Determination of moisture content - Oven dry method - Part 2: Total moisture Simplified method. International Organization for Standardization (ISO). https://doi.org/10.3403/30198053

ISO 18847, 2016. Solid biofuels - Determination of particle density of pellets and briquettes. International Organization for Standardization (ISO).

Jägers J., Wirtz S., Scherer V., and Behr M., 2020. Experimental analysis of wood pellet degradation during pneumatic conveying processes. Powder Technol., 359, 282-291. https://doi.org/10.1016/j.powtec.2019.10.004

Jezerska L., Zegzulka J., Palkovska B., Kucerova R., and Zadrapa F., 2018. Pelletization of invasive Reynoutria Japonica with spruce sawdust for energy recovery. Wood Res., 63(6), 1045-1058.

Kocsis Z. and Csanády E., 2017. Investigation on the mechanics of wood pellet production from sawdust and chips. Progress report $n^{\circ} 6$. Dep. Wood Engineering, University of West - Hungary.

Kruggel-Emden H. and Kacianauskas R., 2013. Discrete element analysis of experiments on mixing and bulk transport of wood pellets on a forward acting grate in discontinuous operation. Chemical Eng. Sci., 92, 105-117. https://doi.org/10.1016/j.ces.2013.01.027
Molenda M., Stasiak M., Moya M., Ramirez A., Horabik J., and Ayuga F., 2006. Testing mechanical properties of food powders in two laboratories - degree of consistency of results. Int. Agrophysics, 20, 37-45.

Moya M., Ayuga F., Guaita M., and Aguado P., 2002. Mechanical properties of granular agricultural materials. Trans. ASAE, 45(5), 1569-1577. https://doi.org/10.13031/2013.11062

O'Sullivan C., Bray J.D., and Riemer M., 2004. Examination of the response of regularly packed specimens of spherical particles using physical tests and discrete element simulations. J. Eng. Mechanics, 130(10), 1140-1150. https://doi. org/10.1061/(asce)0733-9399(2004)130:10(1140)

Oveisi E., Lau A., Sokhansanj S., Lim C.J., Bi X. T., Larsson S.H., and Melin S., 2013. Breakage behavior of wood pellets due to free fall. Powder Technol., 235, 493-499. https://doi.org/10.1016/j.powtec.2012.10.022

Ramírez-Gómez Á., Gallego E., Fuentes J.M., GonzálezMontellano C., and Ayuga F., 2014. Values for particle-scale properties of biomass briquettes made from agroforestry residues. Particuology, 12, 100-106.

https://doi.org/10.1016/j.partic.2013.05.007

Rozbroj J., Zegzulka J., Necas J., and Jezerska, L., 2019. Discrete element method model optimization of cylindrical pellet size. Processes, 7(2), 101. https://doi.org/10.3390/ pr7020101

Saeed A., Farooq M., Andrews G., Phylaktoua H., and Gibbs B., 2019. Ignition sensitivity of different compositional wood pellets and particle size dependence. J. Environ. Manag., 232, 789-795.

https://doi.org/10.1016/j.jenvman.2018.11.122

Salehi H., Poletto M., Barletta D., and Larsson S., 2019. Predicting the silo discharge behavior of wood chips - A choice of method. Biomass Bioenergy, 120, 211-218. https://doi.org/10.1016/j.biombioe.2018.11.023

Schott D., Tans R., Dafnomilis I., Hancock V., and Lodewijks G., 2016. Assessing a durability test for wood pellets by discrete element simulation. FME Trans., 44, 279-284.

Stasiak M., Molenda M., Bańda M., Wiącek J., Parafiniuk P., Lisowski A., Gancarz M., and Gondek E., 2019. Mechanical characteristics of pine biomass of different sizes. European J. Wood Wood Products, 77, 593-608. https://doi.org/10.1007/s00107-019-01415-w

Wojtkowski M., Pecen J., Horabik J., and Molenda M., 2010. Rapeseed impact against a flat surface: physical testing and DEM simulation with two contact models. Powder Technol., 198(1), 61-68. https://doi.org/10.1016/j.powtec.2009.10.015

Wong C., Daniel M., and Rongong J., 2009. Energy dissipation prediction of particle dampers. J. Sound and Vibration, 319(1-2), 91-118. https://doi.org/10.1016/j.jsv.2008.06.027

Wu M., Schott D., and Lodewijks G., 2011. Physical properties of solid biomass. Biomass Bioenergy, 35, 2093-2105.

https://doi.org/10.1016/j.biombioe.2011.02.020

Yazdanpanah F., Sokhansanj S., Lau A.K., Lim C.J., Bi X., Melin S., and Afzal M., 2010. Permeability of wood pellets in the presence of fines. Bioresource Technol., 101, 5565-5570. https://doi.org/10.1016/j.biortech.2010.01.096 